these devices and thus it is necessary to document the ideas and the progress to help the many people now involved in the field.

The authors are to be especially praised on two aspects of the book. One aspect is the inclusion of numerous references, with an author index that includes nearly 300 names. The continuing development of this field will be carried out by many of the authors listed, so that a newcomer to the field will know who to contact for new information. The other aspect is that the authors made a strong, extra effort to become knowledgeable about those specialties of the field in which they had little experience. As a result, the total presentation is uniform and solid in all areas.

I highly recommend the book, especially to all those people new to the field, and would suggest that it be used in advanced courses on the subject.

L. F. EASTMAN

\section{Ring Systems}

Inorganic Rings and Cages. By D. A Armitage. Pp. 387. (Edward Arnold: London, December 1972.) $£ 12.50$.

THIS book will inevitably invite comparison with Allcock's Heteroatom Ring Systems and Polymers (Academic Press, New York and London, 1967), and the exhaustive two-volume treatise by Haiduc, The Chemistry of Inorganic Ring Systems (Wiley, New York and London, 1970). Dr Armitage has confined himself to systems, rings or cages, which do not contain carbon, in contrast with the book by Allcock which, on the other hand, excludes homoatomic systems. The volume under review is more selective but less comprehensive than the one by Haiduc. It will therefore be up to the individual reader to decide which of these three volumes he prefers, as undoubtedly economic necessity will dictate some selectivity. This volume is of course the most up to date of the three and goes systematically right through the main group elements. I found the book most interesting and well worth reading. The literature is covered up to 1970 and each chapter contains an appendix including references from the 1971 literature. Obviously in a book of this size, there must be omissions and I noticed some, particularly in the fields with which I am most familiar. The volume is not always fully referenced and some of the references are placed in such a manner as to be misleading. Quite a number of the names in the reference lists have been misspelt. The book contains a formula index, a specific index of compounds, as well as a general index, but no author index. It is a stimulating, worthwhile book in a field which seems to have begun again to attract the amount of attention it really deserves. This and the other two comparable books all have their merits and are worth buying. Individual research workers and teachers will have to decide for themselves which of these most meets their specific needs. R. A. Shaw

\section{Crystal Defects}

Defects in Crystalline Solids. By B. Henderson. Pp. xi+203. (Edward Arnold: London, December 1972.) $£ 6$ cloth ; $£ 3$ paper.

THIS is the first book to appear in a series entitled The Structures and Properties of Solids, edited by Professor B. R. Coles. The general level is appropriate for mature undergraduates and junior postgraduates in physics, chemistry, metallurgy and materials science. Dr Henderson's text is based on lectures delivered at the University of Keele, and is based towards point defects and small clusters rather than, as tends to be more common in books on defects in solids, towards dislocations and mechanical properties. Following the first chapter, which gives a general introduction to defects, five of the remaining seven chapters discuss point defects in ionic solids, semiconductors and metals. The final chapter describes the interaction of dislocations with other defects, and covers some aspects of slip and hardening. Defects induced both thermally and by radiation are discussed, although there is very little on radiation damage mechanisms as such.

The general layout of the book is good and the material chosen covers a wide range of defect properties. The principal criticism is that there is a large number of misprints and mistakes in the text and equations, which detracts from the usefulness of the book to a beginner in the subject. The experienced reader will easily notice the occasional error, but someone less familiar with the subject could have a frustrating time in places trying to sort his way through mixed notations and inconsistent equations. In one or two places the text is also a bit misleading. For example, the description of the formation of $F_{A}$ centres in alkali halides is at variance with the presently accepted mechanism. How many of these shortcomings are due to the author and how many to the publisher is hard to decide, but in any event it is a great pity that an otherwise excellent book should suffer in this way.

The book should prove attractive to readers interested in receiving an introduction to the science of defects in solids, and it is to be hoped that a second edition will be produced with the errors corrected. A. E. Hughes

\section{Sulphydryl Biochemistry}

Biochemistry of the SH Group: The Occurrence, Chemical Properties, Metabolism and Biological Function of Thiols and Disulphides. By P. C. Jocelyn. Pp. $\mathrm{xx}+404$. (Academic: New York and London, November 1972.) £6.50; $\$ 20$.

THIS small book sets out to cover a very large field indeed. It deals with the properties and functions of low molecular weight thiols and disulphides; with $\mathrm{SH}$ and SS groups in proteins; with the occurrence and functions of these groups in various mammalian tissues, in microorganisms and in plants; and concludes with chapters on radioprotection and pharmacology. The author states that the book is intended primarily for first year university students. However, it is difficult to see how he could get so much information into one small volume in a form which is intelligible to students.

The first 100 pages cover the chemical aspects of the subject. After describing a wide range of naturally occurring thiols and disulphides (including proteins) the author goes on to deal with their physical properties, chemical reactions and methods of estimation. These chapters are good in parts but unfortunately one has to know the subject to know which parts are good. Thus Hopkin's early work on glutathione is given in some detail but the section on analytical methods is unbalanced and fails to give the reader a proper understanding of the principles on which the different methods are based. Equally, hydrogen bonding of sulphur and thiazoline ring formation, which cannot explain the phenomenon of the unreactive $\mathrm{SH}$ group, are given the same weight as hydrophobic bonding, which can.

The latter half of the book, which covers the biological aspects of the subject, suffers from the same deficiencies. Thus the chapter on thiols and disulphides in blood is adequate but the following chapters on their occurrence in animal and plant tissues are little more than lists of headings. The last two chapters on radioprotection and pharmacology could well have been omitted from a book of this level.

The bibliography, containing some 2,000 references, is large for a book of this size but inadequate for the field that is being covered. A sample check showed that one in five of the references contains errors (I am given two sets of initials).

This book could have been very valuable for students if it had covered a more limited field in greater detail and, above all, more critically. In its present form it is misleading for students and inadequate as a source of reference for research workers. $\quad R$. CECIL 